NBER WORKING PAPER SERIES

\title{
THE EFFECT OF EDUCATION ON MEDICAL TECHNOLOGY ADOPTION: ARE THE MORE EDUCATED MORE LIKELY TO USE NEW DRUGS?
}

\author{
Adriana Lleras-Muney \\ Frank R. Lichtenberg \\ Working Paper 9185 \\ http://www.nber.org/papers/w9185
NATIONAL BUREAU OF ECONOMIC RESEARCH
Cambridge, MA 02138 \\ 1050 Massachusetts Avenue \\ September 2002
}

\begin{abstract}
We are very grateful to thank Sherry Glied, Bo Honoré, Christina Paxson, Darren Lubotsky and participants of the NBER Summer Institute for their suggestions. The views expressed herein are those of the authors and not necessarily those of the National Bureau of Economic Research.

(C) 2002 by Adriana Lleras-Muney and Frank R. Lichtenberg. All rights reserved. Short sections of text, not to exceed two paragraphs, may be quoted without explicit permission provided that full credit, including (C) notice, is given to the source.
\end{abstract}


The Effect of Education on Medical Technology Adoption: Are the More

Educated More Likely to Use New Drugs

Adriana Lleras-Muney and Frank R. Lichtenberg

NBER Working Paper No. 9185

September 2002

JEL No. I12, I21

\begin{abstract}
There is a large body of work that documents a strong, positive correlation between education and measures of health, but little is known about the mechanisms by which education might affect health. One possibility is that more educated individuals are more likely to adopt new medical technologies. We investigate this theory by asking whether more educated people are more likely to use newer drugs, while controlling for other individual characteristics, such as income and insurance status. Using the 1997 MEPS, we find that more highly educated people are more likely to use drugs more recently approved by the FDA. We find that education only matters for individuals who repeatedly purchase drugs for a given condition, suggesting that the more educated are better able to learn from experience.
\end{abstract}

\author{
Adriana Lleras-Muney \\ Princeton University \\ Department of Economics \\ 320 Wallace Hall \\ Princeton, NJ 08540 \\ and NBER \\ alleras@princeton.edu
}

Frank R. Lichtenberg

Columbia University

Graduate School of Business

726 Uris Hall

3022 Broadway

New York, NY 10027

And NBER

frank.lichtenberg@columbia.edu 
The National Center for Health Statistics reported in 1998 that "the chronic disease death rate for men with a high school education or less was 2.3-2.5 times that for men with more than a high school education". Similarly strong, positive correlations between education and different measures of health (while controlling for income, occupation and other individual characteristics) have been documented by a large number of studies (see Grossman and Kaestner, 1997 for a review). There is some evidence that education has a causal impact on health, i.e. that more education makes one healthier (Berger and Leigh 1988, Sander 1995, Leigh and Dhir 1997, Goldman and Lakdawalla 2001 and Lleras-Muney 2001). Some studies even suggest that the health gap across education groups has been rising over the past 30 years (Feldman et al. 1989, Pappas et al. 1993, and Elo and Preston 1996). However, little is known about the many potential causal mechanisms by which education might affect health. ${ }^{1}$

This paper explores one possibility: that more highly educated individuals are more likely to adopt new technologies, and that they are better at implementing those new technologies as well. In 1966, Nelson and Phelps suggested that "educated people make good innovators" and that "education is especially important to those functions requiring

\footnotetext{
${ }^{1}$ Goldman and Lakdwalla (2001) show that the more educated choose more patientoriented treatment and are better at using these treatments. This evidence supports Grossman's 1972 "productive efficiency" hypothesis. Kenkel (1991) and Meara (2001) provide evidence that the more educated have more information and use that information better. But the effect of education is not fully accounted for in these studies.
} 
adaptation to change". Using a panel of manufacturing industries in the U.S., Bartel and Lichtenberg (1986) showed that more educated individuals also had an advantage in implementing new technologies (i.e. in learning how to use those technologies more effectively), given adoption.

But the relationship between education and medical technology has not been explored. ${ }^{2}$ Since the medical field is one of the most active in terms of innovation, ${ }^{3}$ it is important that we understand how these innovations are used by and diffused among consumers. If the more educated are better able to adopt new medical technologies, then the introduction of new technologies will generate a health gap across education categories, ceteris paribus. This gap could increase overtime if the rate of innovation increases (and if innovations benefit all individuals equally). Since these predictions are consistent with the stylized facts, this theory seems worthy of investigation.

The challenge when looking at technological change consists in finding reasonable measures of innovation. Following Lichtenberg (2000a), we use the age of a drug, defined as the number of years since FDA approval, as a measure of innovation in medical technology. Given

\footnotetext{
${ }^{2}$ With the important exception of analyses of the effect of health information such as the effect of the Surgeon General's report on smoking.

${ }^{3}$ The ratio of $R \& D$ expenditure to total expenditure is higher for health $(3.6 \%)$ than it is for the economy as a whole (2.6\%). Moreover, pharmaceuticals-the focus of our analysis - is much more R\&D-intensive than other health care expenditure. (Sources: Science \& Engineering Indicators, and Health, United States.)
} 
that newer drugs embody advances in the medical field ${ }^{4}$ and are more effective, then the more educated should be healthier as a result of their using newer drugs. The advantage of looking at prescription drugs then is that we can know the date of innovation for all drugs. Therefore this study goes beyond other studies of innovation adoption because it is not limited to a particular case study.

The specific question we address in this paper is whether more educated people are more likely to use newer drugs, controlling for other individual characteristics, such as income and insurance status. A simple correlation between education and the age of drugs could be easily explained due to the fact that new drugs are more expensive, and the more educated have higher incomes and are more likely to be insured. We are not interested in such indirect effects of education. Rather, we are interested in the behavior of the more educated with respect to their health, conditional on income and insurance, since this is the correlation that most studies have documented. If we find that education affects health independent of income and insurance, the policy implications are very different than the case where education matters only because of income.

We use the 1997 MEPS to answer our question. This is a highly detailed data set which contains information on individuals, their conditions, and the drugs they take. Even after controlling for many

\footnotetext{
${ }^{4}$ Lichtenberg $(1996,2001)$ has shown that newer drugs are of higher quality: they are more effective at reducing mortality, morbidity and total medical expenditures.
} 
factors, we do indeed find that the more educated use drugs more recently approved by the FDA. We also find that education only matters for individuals that repeatedly purchase drugs for a given condition, suggesting that the more educated are better able to learn from experience.

This paper is organized as follows. The next section discusses in greater detail many possible mechanisms through which education might affect health. Section II presents the data. Section III presents the basic results and a number of additional estimates. Section IV concludes.

\section{I-What is the mechanism by which education affects the age}

\section{of the drugs taken?}

One reason why the more educated are more likely to adopt a new medical innovation is that they are better informed. According to a 1999 National Science Foundation survey, $32 \%$ of those with more than a college degree declared they were both very interested and very well informed about new medical discoveries, whereas only $14 \%$ of those with less than a high school degree did. ${ }^{5}$

But differences in access to information alone are not the only reason why we might expect differences in medical technology adoption across education categories. Conditional on equal information, different subjective evaluations of the risk and benefits of new technologies should

\footnotetext{
${ }^{5}$ From Science and Engineering Indicators 2000 , published by the National Science Foundation. The report can be found at the following website:

http://www.nsf.gov/sbe/srs/seind00/access/toc.htm
} 
result in differential adoption. There is some evidence that the evaluation of new technologies differs by education levels. In 1999, $71 \%$ of those with a college degree or higher thought that the benefits of new technologies strongly outweigh the harmful results, whereas only $25 \%$ of those with less than a high school degree thought so. ${ }^{6}$ The question of why such evaluation is different across education categories might be related to the understanding of science. For example, the National Science Foundation estimates that $53 \%$ of those with more than a college degree understand the nature of scientific inquiry, whereas only $4 \%$ of those with less than a high school degree do. ${ }^{7}$ This type of knowledge does not directly relate to any particular innovation but more generally helps individuals process information about all innovations better. Presumably this knowledge is acquired in school.

Rosenzweig (1995) gives additional insights into why a relationship between education and technology exists. Education not only improves the ability to understand information but it enhances the ability to learn from experience and observation. If the more educated are better at learning then education will make a difference in situations where learning is possible, such as in the case of chronic conditions. Lakdawalla and Goldman (2001) and Case et al. (2001) do indeed find that education

\footnotetext{
${ }^{6}$ ibid.

${ }^{7}$ ibid. The level of understanding of scientific inquiry was determined from answers to three questions. One question ask people if they understood scientific study and ask them to describe the methodology. Another question ask people if a controlled experiment was a better way to evaluate the impact of a treatment than other data and they were asked why. Finally the last set of questions assessed the individual's understanding of probabilities.
} 
matters more for chronic diseases. In the case of prescription drugs, one would expect that among consumers with chronic conditions, the more educated will be better at identifying the most effective (i.e. the newest) drugs.

Another implication of the learning theory, is that the more complex a particular technology is (and therefore the higher the potential gains from learning), the higher the advantage of the more educated will be. In other words, the benefits of new technologies could also be higher for the more educated (although note that there is evidence to the contrary in the case of drugs, see Lichtenberg and Virabhak, 2002). Rosenzweig and Schultz (1989) provide an example by comparing success rates of different contraception methods for women with different levels of education: success rates are identical for all women for "easy" methods such as the pill, but the rhythm method is only effective for educated women. ${ }^{8}$ Admittedly, new drugs may be easier to use-e.g. once a day rather than several times a day. So according to this argument differences between education groups should persist only for complex drug treatments.

The previous section suggests that the main effect of education on drug adoption is related to differences in information, differences in perceptions of technological progress, differences in learning and in the potential gains that accrue to the more educated depending on the

\footnotetext{
${ }^{8}$ Goldman and Smith (2001) provide additional evidence that the more educated are more likely to adhere to treatments.
} 
complexity of the innovation. There are several other mechanisms, more specifically related to the use of prescription drugs, that could lead us to find a positive relationship between education and the vintage (FDA approval year) of the drug consumed.

One important issue is whether or not there is any choice at all with respect to drug choices or drug adoption. It is important to emphasize here that today, there are many different drugs available to treat the vast majority of conditions. Using the National Drug Data File (see data appendix for details), we calculate that the average number of drugs that are available to treat a condition is 4.74 . Furthermore, the number of drugs available is larger for the more prevalent conditions. This statistic is calculated by looking at the condition that the FDA approved the drug for. In reality, drugs are taken to treat many more conditions than they were originally approved for. So if we calculate the same statistic using the MEPS, we find that on average there are 22 drugs used for a given condition! $!^{9}$ The important point here is that there exists a choice of drug.

A different question is whether the choice of prescription drug is made by the patient. One possibility is that doctor and patient jointly decide what drug is most appropriate to treat the condition if there is a choice among different drugs. Another hypothesis is that individuals have no choice with respect to the prescriptions they take-these are chosen entirely by their physician-but individuals do select their physicians. It

\footnotetext{
${ }^{9}$ Note that this average is weighted by prevalence and also reflects the larger variety of uses for which drugs are eventually prescribed.
} 
is possible that the more educated select better doctors, who are better informed about new innovations or more willing to prescribe newer drugs. Alternatively, it is possible that individuals will switch doctors if they are not being prescribed the drugs that they want to consume.

There is anecdotal evidence that suggests that all of the above occur. There is evidence that patient demand influences doctors' prescribing behavior. In their 1989 study, Schwartz et al. found that "patient demand for drugs, whether for a specific preparation or for a prescription in general, was the most frequently cited motivation (46\%) for nonscientific prescribing". ${ }^{10}$ On the consumer side, recent evidence on the effect of direct-to-consumer advertising suggests that consumers respond to such advertising and ask their doctors about the prescriptions advertised on television. ${ }^{11}$ These studies suggest that patients can have an important influence on their doctors' prescribing behavior. Also note that there is wide variation in the prescription behavior of doctors, and in the rate at which doctors start prescribing new drugs (see review by Bradley, 1991). Another way to exercise choice consists in changing physicians.

\footnotetext{
${ }^{10}$ The study found that "physicians also frequently attributed their prescribing of these drugs to intentional use of placebo effect."

${ }^{11}$ A recent study by the Kaiser Foundation analyzed prescription drug consumer behavior since the partial "ban" on direct-to-consumer advertising was lifted in 1997. It found that "Among the $30 \%$ of Americans who said they talked to their doctor about a medicine they saw advertised in the past, $44 \%$ say that the doctor gave them the prescription medicine they asked about". The majority of those who did not consult their physician about the advertised drugs were not actually affected by the condition treated by the drug. This evidence is not uncontroversial however. The FDA reports that only $2 \%$ of people who visited a doctor in the last 3 months during which there was a conversation about a prescription drug did so because they "read or saw something" (e.g. an advertisement for a drug). See question 17 of http://www.fda.gov/cder/ddmac/dtctitle.htm.
} 
Legal evidence documents that patients change doctors to obtain different prescriptions (See Temin, 1980) or that they obtain prescription medicine illegally (the most recent example being the use of Oxycontin ${ }^{12}$ ).

In a similar vein, perhaps the choice of drug is made by the insurance company or HMO. ${ }^{13}$ Yet again it is possible that the more educated choose better health care insurance plans, with more choices among potential doctors and greater prescription drug coverage. Although health insurance is mostly provided through employers, in $1999,47 \%$ of those employed declared that they had a choice of health care plans. ${ }^{14}$ Furthermore individuals can switch health insurance plans. In 1996-97 however, only about $8 \%$ of those that changed health plans did so to obtain better services. This channel is therefore plausible but perhaps less likely. But among those that changed plans, the more educated did so at higher rates (see Cunningham and Kohn, 2000).

A final possibility is that newer drugs are developed by pharmaceutical companies for the more educated because the more educated also are wealthier (although we control for income and wage).

\footnotetext{
${ }^{12}$ Meier, Barry, "Overdoses of Painkiller Are Linked to 282 Deaths" The New York Times October 28, 2001, Sunday.

${ }^{13}$ The work by Baker (2000), and Baker and Phibbs (2000) suggests in fact that the rate of technology adoption has been affected by managed care. But since the more educated appear to be more likely to belong to an HMO, and HMOs appear to adopt new technologies at a slower pace (Baker, 2000, and Baker and Phibbs, 2000), we are potentially underestimating the true effect of education. See Benjamini and Benjamini (1984). Using the 1996 MEPS, we find that the more educated are more likely to belong to an HMO : among those with insurance, $21 \%$ of men without a high school degree belong to an $\mathrm{HMO}$, where as about $53 \%$ of those with a Ph. D. do (for women the difference is $29 \%$ against $58 \%$ ). We thank Sherry Glied for providing this information: The data on HMO is not part of the MEPS public files so we could not calculate these numbers ourselves.
} 
Note however that new drugs are developed for particular diseases. If pharmaceutical companies target diseases of the rich and educated, we would indeed observe a correlation between education and the age of the drug. But this correlation would disappear once we control for condition.

\section{II-Data}

To analyze prescription drug consumption, we use the Medical Expenditure Panel Survey (MEPS) for $1997 .{ }^{15}$ The MEPS is an individuallevel survey containing information on demographic characteristics (such as age, sex, race, education, income, etc), insurance status, and drug use (including drug price, who paid for the drug, the condition for which the drug is taken, and how long the person has had the condition). ${ }^{16}$ Since we are interested in the effect of completed years of schooling, we restricted the sample to individuals age 25 and above that used at least one prescription drug in 1997 and had no missing observations.

The MEPS data were collected in modules. The information on prescription drugs is in a separate file from the person data and the condition data. Each individual can be potentially matched to several conditions and each condition can be matched to several prescriptions. In the final data, every prescription, including refills, constitutes an observation. Thus an individual will appear potentially several times in these data.

\footnotetext{
${ }^{14}$ From the Commonwealth Fund 1999 National Survey of Workers' Health Insurance. See Duchon et al. (2000).

${ }^{15}$ The 1996 MEPS data is also available but in our conversation with the AHRQ they suggested that the prescription data for 1996 should not be used.
} 
Data on drug approval dates come from several sources, but were mostly obtained by filing a freedom of information act request with the FDA (see Data Appendix). The FDA provided a list of all new drug approvals since 1938 (the year when the FDA came into existence). We determined from the FDA list the date at which the FDA first approved all of the approximately 2000 active ingredients contained in drugs consumed in 1997. For each medicine we calculated the age of the drug as the number of years prior to 1997 that the active ingredient(s) in the prescribed drug was first approved by the FDA. Although prescribed medicines can contain one or more active ingredients, more than $3 / 4$ of the drugs in our list are single-ingredient drugs. The average number of active ingredients per drug is 1.27. For medicines with multiple active ingredients we calculated the average age across all ingredients.

The reason why we use the year when the active ingredient was approved rather than the year when the drug was approved is that we consider the approval of active ingredients to be the most important innovation. The FDA also approves generic equivalents, and new dosage forms of already existing drugs. There is a very large difference between the number of drugs and innovation: today there are about 80,000 different drugs, but only about 2000 different active ingredients.

Graph 1 shows the number of active ingredients approved each year since the FDA's inception. Note that many ingredients were first approved soon after the FDA was established. Most of the ingredients contained in

\footnotetext{
${ }^{16}$ See Appendix for details about the MEPS data we use.
} 
these products had already been discovered and were being used prior to 1938. Year of approval is not a good measure of the innovation date for the early years, but this phenomenon is not very important after 1943 (approximately). Also note that we have some ingredients with an approval date of 1930.1930 was an arbitrarily chosen date for drugs that existed prior to 1938 and never came to be approved by the FDA. The actual innovation date is unknown.

We link MEPS data with data on drug age from the FDA using drug NDC codes, which uniquely identify all drugs available in the market. The summary statistics for the final data are presented in Table 1. These statistics are also presented for those with a high school degree or more, and for those with less than a high school degree.

The average age of drugs in the sample is about 25 years. The mean is slightly higher for the less educated but not much. However these two groups are very different on a number of other dimensions: the less educated are also older, more likely to be single, to live in rural areas, to be poor, and to be in poor health (they are more likely to report in poor health, they have a higher number of hospital visits and they have higher total health care expenditures). The means comparisons preview our regression results: the difference in the age of the drug is affected by education but the effect is not large.

Several important statistics are not presented in the Table. The minimum drug age in our data is -4 . Although this might appear strange, 
we do observe individuals consuming drugs in 1997 that were approved only in $2001 .^{17}$ There are 12,431 individuals in the data and 163,081 prescription-level observations. So the average number of prescriptions per person is around 13. The average number of conditions per person is about 2.6. So individuals are consuming about 5 prescriptions per condition. This number might appear high at first but recall that it includes refills. It is not clear whether is appropriate to use refills but we note that the results presented below are very similar if we estimate all regressions using means at the person level. ${ }^{18} \mathrm{We}$ present prescription level results here since the prescription level data contains more information, such as the amount the individual paid for the drug.

\section{III-Results}

\section{1-Basic Results}

We estimate the following model, which estimates whether education decreases the age of the drug taken, conditional on taking a drug:

$$
\operatorname{Age}_{\mathrm{dci}}=\beta \mathrm{X}_{\mathrm{i}}+\mu \mathrm{P}_{\mathrm{dci}}+\alpha_{\mathrm{c}}+\varepsilon_{\mathrm{dci}}
$$

where Age $_{\mathrm{dci}}$ is the average age (measured in years) of drug d taken by individual $\mathrm{i}$ for condition $\mathrm{c}$; $\mathrm{X}_{\mathrm{i}}$ are characteristics of the individual taking the drug, such as education, personal income and insurance status (these characteristics do not change across drugs for the same individual); $\mathrm{P}_{\mathrm{dci}}$ is a set of prescription level variables such as the percentage of the total

\footnotetext{
${ }^{17}$ These individuals were maybe part of clinical trials.
} 
amount paid by the individual for this drug; and $\alpha_{c}$ is a set of 3-digit level condition dummies. In all the estimation we cluster the errors at the person level and we use the person weights provided by the survey. ${ }^{19}$

We control for detailed disease categories because innovation varies significantly across diseases. The theory suggests that the more educated will use newer technologies to treat the particular disease they are affected with. The latest drug for condition i might be years older than the latest drug for condition $\mathrm{j}$. Since the distribution of diseases also varies across education, the results could be biased if we fail to control for condition.

Table 2 presents the results. We find that one more year of education lowers the age of the drug by 0.16 years. This effect is statistically significant at the $1 \%$ level, but it is not very large given that the mean age of drugs in the data is 25 years. Also this effect is small when compared to other coefficients in the regression: for example, being white or having private insurance decreases the age of the drug by 1.6 years. The economic magnitude is discussed further below.

One important issue is that, as we discussed in the data description, the true age of the drug is censored for drugs that were approved prior to 1943. We estimate a linear probability model where the dependent variable is whether or not the drug was approved after 1970, 1980 and 1990 (columns 2, 3 and 4). As expected we find that the effect of

\footnotetext{
${ }^{18}$ Results available upon request.

${ }^{19}$ Our results are not very sensitive to the use of weights.
} 
education is positive and significant for all three specifications. We also estimate the model using a Tobit specification to account for censoring ${ }^{20}$ (Column 5). In this specification, the effect of education is somewhat smaller but it is still negative and statistically significant.

Finally, we address some issues concerning measurement of the age of drugs. When constructing the data for the age of the drugs, we made a series of imputations (see Data Appendix). If this measurement error is random then it should not bias the regression coefficients at all. If it is not random then the sign of the bias depends on the form of the measurement error. We constructed a dummy variable equal to one if the age of the drug was imputed, and equal to zero if the age of the drug was known. The coefficient on this variable is positive and significant suggesting most imputations we made were for older drugs. Including this variable in our regression (last column in Table 3) has no significant impact on the coefficient on education however.

Although not reported in the table, we also estimated additional model to test the robustness of the results for different measures of drug vintage. Estimations that drop drugs for which drug age is imputed, use date of approval of the main new molecular entity (instead of the approval of the main active ingredient), or look only at priority drugs (the FDA has a different schedule for drugs it considers more innovative), yielded identical coefficients to those reported here.

\footnotetext{
${ }^{20}$ We censored the age at 54 , under the assumption that, as discussed in the data description, the true innovation date is known after 1943.
} 


\section{2-The effect of income and insurance}

An important issue is whether we can distinguish the effect of education from that of income. Newer drugs are more expensive than older drugs (see Graph 2), and the more educated are also wealthier. Given that many individuals do not have insurance, a positive correlation between age of a given drug and education could solely reflect differences in income or borrowing constraints. All previous estimates controlled for insurance status and income. But of course measures of income are usually noisy, and insurance does not pay for all medical expenses. Also note that insurance requires co-payments to be made for each purchase, and the co-payment might be higher for newer drugs (since newer drugs are more expensive). Graphs 3 does indeed document that individuals pay more for newer drugs (except prior to FDA approval, so for ages -4 to -1).

However the issue here is whether the less educated pay more out of pocket for newer drugs. Lichtenberg and Phillipson (2001) find that "drugs purchased under Medicaid [by low-income persons] are fairly representative of all US drug transactions, at least in terms of price." This suggests that access to new (expensive) drugs by low-income (low education) individuals (at least those covered by Medicaid) may not be that limited. Graphs 4 and 5 show indeed that payments for prescription (either total payments or percentage paid by self) are not higher for the uneducated. Graphs 6 and 7 suggest an explanation: private insurance covers a much larger percentage of prescription drugs for the educated, 
but on the other hand Medicaid pays a large percentage of prescriptions for the uneducated.

To further investigate this issue, we estimate the model again using different specifications (table 3 ). Column 1 reproduces the basic results form Table 1. In column (2) we add the percentage of the prescription that the individual paid. The amount paid by the individual captures the marginal cost to the individual and is perhaps the more relevant measure (although it might be endogenous since people can move away from drugs not covered by insurance). This variable is positive and very significant: if the individual's percentage payment increases by $10 \%$, the age of the drug increases by 0.6. However note that the inclusion of this variable increases, rather than decreases, the coefficient on education.

Next, we add the percentage of prescription drug expenditure that the individual (or his family) paid for out-of-pocket over the year. This variable captures the extent of prescription drug coverage that the person has. Its effect is positive and significant: if the fraction of drug expenditure borne by the individual increases by 10 percentage points, the age of the drugs they use increases by 0.25 years. But interestingly the inclusion of this variable has no impact on the coefficient of education.

To fully account for the effects of insurance, we break down insurance further into several components. In column 4 we estimate models that include the percentage of total health expenditures paid over the year from several sources. We find (as suggested by Graphs 6 and 7) 
that Medicaid coverage and private insurance result in newer drug purchases (although only the later is statistically significant). Again, the effect of education does not change much by adding these controls.

Note that we assume that insurance can be taken as exogenous in these specifications, which need not be the case as we discussed in Section 2. However there is some evidence this is a plausible assumption for prescription drugs. ${ }^{21}$ There is no evidence that we know of about whether income can be taken as exogenous in our specification. However, if we estimate our basic model and control only for gender, race, and age, we find that the effect of education is about -0.211 and significant.

As a last attempt to control for access, we estimate a model including the number of physician visits in the year. Presumably prescription drugs are obtained after visiting a doctor. Those individuals that do not have good access to doctors (because they are poor or uninsured) would presumably not use prescription drugs. ${ }^{22}$ The last column of Table 3 shows the results. The number of physician visits is insignificant and does not alter the coefficient of education. Note that this variable can also be thought of as a measure of the severity of the illness, an issue that we discuss below.

\footnotetext{
${ }^{21}$ For example, Lillard, Rogowski and Kigton (1999) conclude that insurance is exogenous in a model of the effect of drug coverage on drug use and out of pocket expenditures for drugs. Coulson et al. (1995) conclude that insurance decision is exogenous to the demand for drugs.

${ }^{22}$ And there would not be in our sample unless there are consuming refills, or they obtain the prescription after a hospital visit. We still believe that the number of visits to the doctor is a good measure of access among those that have some access.
} 
It is worth commenting about how we think of the issue of drug prices. Although we observe the total amount of payments made for the prescription, which can be thought of as the price paid for the drug, we do not include it in our estimations ${ }^{23}$ because the standard economic models suggest that the relevant price information consists of the quality adjusted relative price of the new drug (compared with other drugs for the same condition), which we don't observe. Furthermore if all individuals faced identical price schedules then we could not estimate the effect of price using a cross section. But since there is price discrimination in the drugs market, ${ }^{24}$ individuals do face different price schedules, which again we do not observe. However we do control for detailed insurance coverage, which is one of the reasons (in addition to location) why individuals face different relative prices for the same drugs.

Finally, although we find that the effect of education remains even with detailed controls for income and insurance, one possible interpretation of our results is that education is capturing the effect of permanent income or wealth rather than the effect of education itself. This is possible since we only observe annual income, which is prone to measurement error and at best is only a measure of current income. We do not have data that allows us to construct permanent income measures. But

\footnotetext{
${ }^{23}$ We did estimate a model using total amount paid for prescription at the prescription level. The effect of education was unchanged in these estimations. Results available upon request.

${ }^{24}$ Different individuals pay different amounts for the same prescription drug depending on their insurance plans and the prices that particular pharmacies offer. Sorensen (2001) documents that "[prescription drug] prices vary widely across stores,
} 
we note here that others have found that the effect of education on health does not disappear once permanent income or wealth is accounted for. ${ }^{25}$

\section{3-controlling for severity}

It is reasonable to hypothesize that the more seriously ill have greater access to newer drugs. Our data, like previous research, ${ }^{26}$ suggests that the less educated are more likely to be seriously ill (recall the discussion in the data description). Therefore we could be underestimating the effect of education. Note however that the inclusion of severity measures is not without problems since severity variables are possibly endogenous: those without access to newer drugs will become sicker. Nonetheless, we add several controls for severity.

The results are in Table 4. First we include the number of times the person visited the hospital over the year. Then we include a dummy if the individual self reported to be in bad health and, finally, we add total health expenditures over the year. None of these measures is significant at the $5 \%$ level, nor does their inclusion affect the coefficient on education. Interestingly note that the effect of hospital is positive-consistent with

and stores' price rankings are inconsistent across drugs (so the low-price pharmacy is different for one prescription vs. another)".

${ }^{25}$ Meer et. all (2001) show using instrumental variables that the effect of wealth on health is not causal. In their regressions education (lack thereof) is always significant. Hurd et al. (2001) also show that for some health measures education as well as wealth appear to have causal impacts on health. Case et al (2001) find that parent's education affects children's health net of permanent income: for older kids mom's education is significant (not dad's) and for younger kids, dad's education is significant (not mom's). (these results are not part of the current version of their paper but Anne Case kindly made them available to me). Although our outcome of interest is not health, this evidence is suggestive that the effect of education is not solely capturing the effect of permanent income or wealth.

${ }^{26}$ For example see review by Adler and Newman. 
Lichtenberg (1996, 2001)—suggesting this variable may be endogenous (i.e. taking newer drugs reduces the probability of hospital admission). ${ }^{27}$

\section{4-Variation across conditions in the effect of education}

Although our data do not allow us to test all the mechanisms by which education affects the age of the drug consumed, we can test one hypothesis, that education matters only or primarily where learning is possible, i.e. for chronic conditions. In the MEPS data, we do not have information about whether conditions are chronic or acute. And unfortunately information on how long the person has had the condition is missing for a large part of our sample. So we cannot simply categorize conditions into acute and chronic. We can however test the hypothesis in two ways. First, we can estimate separate regressions by condition to see whether the effect of education is larger for conditions that are usually classified as chronic. Alternatively, we look at whether the effect of education is larger for individuals who repeatedly purchase drugs for a given condition.

We first estimate regressions separately by broad disease categories (Table 5). We find some evidence to support the learning hypothesis: the effect of education is negative and significant for chronic diseases such as diseases of the nervous system, mental disorders and cardiovascular diseases. The effect is positive and insignificant for several diseases that are generally acute such as all infectious diseases and disease of the

\footnotetext{
${ }^{27}$ The MEPS also contains information about when the individual first became sick, but we did not use it because it is missing for a large number of observations.
} 
digestive and genitourinary system. However there are a couple of odd results: we find a positive effect for cancers, which are chronic diseases and we find a negative effect for respiratory diseases, several of which are acute. However we note that these categories are very broad and so this is not a clear test of the acute versus chronic condition effect. At the bottom of the table we re-estimate regressions for chronic diseases for which we have many observations at the three digit level. We confirm that the effect of education is negative for hypertension and chronic sinusitis, but again we find that the effect of education is positive (although small and insignificant) for diabetes and depression.

To further investigate this hypothesis we look at whether the effect of education is larger for those people who repeatedly purchase drugs for a given condition. The MEPS contains information about the number of prescriptions that the individual reports to have taken over the year for each of his conditions. This is probably a good, but by no means perfect, indicator of whether the condition is chronic. If the more educated can learn better from experience, we should observe that the effect of education is larger for those who repeatedly purchase drugs for a given condition. First we estimate the results for three different groups: those that have only 1 prescription for the condition, those that have between 2 and 6 prescriptions and those with 7 or more prescriptions for the condition. Note that the median number of prescriptions per condition is 3. The results are presented in Table 6 . 
We find strong evidence to support our hypothesis. The effect of education is positive and insignificant for those with only one prescription for the condition, it becomes negative and significant for those with 2 to 6 prescriptions by condition and it increases to -0.269 for those who use more than 7 prescriptions. In the last column of Table 6 we re-estimate the model pooling all individual together and interacting education with the $\log$ of the number of prescriptions by condition. ${ }^{28}$ Again we find that the effect of education is larger for those who use many prescription. These results are consistent with the learning model.

\section{5-Effects of education for different demographic groups}

There are large differences in a variety of health outcomes between different demographic groups. We therefore re-estimate the model by race and gender in Table 7. The effect of education is negative for both genders, although the effect is larger and only statistically significant for males. We also find that the effect of education is large and significant for whites, and small and insignificant for blacks, but the sample is smaller for this last group. Both of these findings are consistent however with previous findings in the health literature, which suggest larger effects of education on health for whites and for males (for example see Elo and Preston, 1996 and Christenson and Johnson, 1995).

\section{6-Is the effect causal?}

\footnotetext{
${ }^{28}$ We chose a log specification because the previous results suggest the effects are non-linear, but the results are very similar if we use a linear specification.
} 
So far we have assumed that the measured effects of education reflect the fact that the more educated use newer drugs, i.e. we have given the education effect a causal interpretation. This need not be the case.

One possibility is that there is omitted variable bias. Perhaps education captures differences in unmeasured ability. In additional estimations not reported here, we added wages to capture differences in ability. They were never significant, nor did their inclusion affect the coefficient on education. But of course wages are only a proxy for ability.

Perhaps there are also differences in discount rates: the more patient individuals invest more in education and health, with investment in health being captured by the use of newer drugs. Alternatively there could be some form of reverse causality: those that don't use new drugs are sicker when growing up, and they obtain less education. Unfortunately no instruments are available, ${ }^{29}$ so our results must be interpreted with caution. We note nonetheless that, as stated in the introduction, other studies provide evidence that there is a causal effect of education on health, consistent with our results.

\section{IV-Conclusions}

This paper has shown a robust relationship between education and the age of drugs consumed. The MEPS data allowed us to control for a variety of detailed individual characteristics, the majority of which had no 
impact on the estimated effect of education. The evidence presented in this paper does strongly suggest there is differential adoption by the more educated. Importantly, we also find that the effect of education is larger for individuals who repeatedly purchase drugs for a given condition. This result suggests that the more educated are better able to learn from experience.

However, the effect of one more year of schooling on the age of the drug consumed is small. Nonetheless we note here that in the absence of Medicaid the relationship between education and drug age might be much larger. It is impossible for us to actually test this hypothesis but the evidence presented here certainly suggest that access to newer drugs by uneducated poor consumers might be much lower if Medicaid did not provide prescription drug coverage.

How important is the effect of education on health because of use of newer innovations? This question is difficult to answer, in part because in order to evaluate the impact of new drugs on health one needs to know not only whether the more educated adopt first but also how much they benefit from new innovations. Evidence from Lichtenberg and Virabhak (2001) suggests that the less educated benefit more form new drugs. We find that they are also late adopter. Overall it is unclear what effect innovation might have on the health gap. Nonetheless we note here that ceteris paribus (i.e. if everyone benefits identically from new

\footnotetext{
${ }^{29}$ We investigated different possibilities with the MEPS, but we failed to find instruments that would satisfy the usual criteria. Results available upon request.
} 
innovations), then differential adoption can only explain a small part of the education-health gap. We calculate that a ten-year increase in education decreases the average age of the drug taken by 1.6 years. Using results from Lichtenberg (2001b), we calculate that this decrease results in a life expectancy gain of .0475 years, or about 2.5 weeks. This is a very small gain from a large increase in education.

Nonetheless, our results do suggest that the more educated use newer medical technologies, controlling for income and insurance. We have documented the effect in one area of medical innovation: drugs. Given that prescription drugs is a realm where individuals may have relatively little choice, it is quite possible that the effect of education is larger in other areas where choice is more important. Also note that although newer drugs are important innovations in terms of their effects of health, other innovations in the medical field in recent years may have had larger impacts on health (see Fuchs and Sox, 2001). In these areas, therefore, the effect of education on health via technology adoption may be larger. Finally we believe these results are important in that they document that the more educated have fundamentally different behaviors with respect to health. This paper is a first step in understanding how education affects health.

We note however a couple of caveats to our analysis. We cannot claim with confidence that our results represent causal estimates of the effect of education given that we do not have good instruments in our 
data. But the results do suggest that unobservables may not be very important. Also, even with the detailed data available in the MEPS we cannot investigate all the possible mechanisms by which education affects the age of the drugs consumed. We find evidence to support the hypothesis that education matters for situations where learning is possible, such as for chronic diseases. On the other hand, we do not know if the educated have access to better information about new drugs, or if they perceive them to be more effective. Additionally there are other hypothesis we cannot test, such as whether the educated use drugs more effectively or whether they change doctors in order to obtain the prescriptions they want. Work in these directions would provide very useful insights about how education changes individual behaviors towards health and health production. 


\section{Data Appendix}

\section{Data on drug approval}

Each drug used by individuals in the MEPS was assigned an age that was calculated using the FDA date of approval of the active ingredient(s). Most drugs are composed of a unique ingredient-for drugs that contain more than one ingredient we calculated the average year of approval.

The FDA provided the date at which all active ingredients were approved. There were several ingredients in the data for which approval date was not available. Some dates were imputed as follows:

-we imputed the date if the name of the ingredient was very similar to the name of another FDA active ingredient for which we have a date. We interpret the FDA lack of data on a similar ingredient as meaning that the FDA does not consider it a separate ingredient. For example, the FDA has an approval date for adenosine (1988) but provides no data for adenosine phosphate, adenosine 5 monophosphate, adenosine 5 triphosphate disodium, so we interpret that FDA considers all these the same compound (adenosine) and imputed a 1988 date for them.

-Mosby (a private company) provided another list of FDA approval dates that was used to impute the dates that were still missing. We used this list to manually replace an additional 27 cases.

-No attempt to impute missing dates for those ingredients that never appear in the prescribed medicine event, to this extent our data on approvals might not be yet as complete as possible.

Data on drug approval year was matched to NDC codes by active ingredient. Multum Information Services provides data that matches drugs to active ingredients using the unique NDC drug code. This data are available from the internet at: http://www.multum.com. Then the data was matched to the prescribed medicine 1997 MEPS data by NDC code. 
There were about 1500 cases that couldn't be matched due to errors in the NDC codes in the prescribed medicine event file. We imputed the active ingredient (and therefore the approval date) for the majority of these cases using the name of the drug (the MEPS provides that name).

Because of these imputations, we are concerned about the effect of measurement error. We therefore created an additional variable "imputed" that is equal to one if the date was imputed at all, that we use in some of the analysis.

\section{MEPS data}

We use the following MEPS components for 1997: Person data file (HC020), prescription event data (HC-016A) and condition data (HC-018). The prescription and the condition data are merged using the linking files (HC-16IF1). We keep only those observations for which there is prescription and condition data. 


\section{Bibliography}

Adler, Nancy E. and Katherine Newman, forthcoming, "SES Disparities in Health. Pathways and Policies" Health Affairs

Baker, Laurence C, November 2000, "Managed Care and Technology Adoption in Health Care: Evidence from Magnetic Resonance Imaging," NBER Working paper W8020

Baker, Laurence C and Ciaran S. Phibbs, September 2000, "Managed Care, Technology Adoption and Health Care: The Adoption of Neonatal Intensive Care," NBER Working paper W7883,

Bartel, Ann P. and Frank R. Lichtenberg, February 1987, "The Comparative Advantage of Educated Workers in implementing new technology," the Review of Economics and Statistics, pp.1-11

Benjamini, Yeal and Yoav Benjamini, September 1984, "An Empirical Study of the Choice Among Medical Insurance Plans," Working paper

Berger, Mark C. and J. Paul Leigh, 1989, 'S Schooling, Self Selection and Health," Journal of Human Resources, Vol. 24, pp.433-455

Bradley, Colin p., 1991, "Decision Making and Prescribing Patterns-a Literature Review," Family Practice, Vol. 8, No. 3, pp. 276-287

Case, Ann, Darren Lubutosky and Christina Paxson, March 2001, "Economic Status and health in Childhood: the origins of the gradient," Center for Health and Well being Working paper

Christenson, Bruce A. and Nan E. Johnson, May 1995, "Educational Inequality in Adult Mortality: An Assessment with Death Certificate Data from Michigan," Demography, Vol. 32, No. 2, pp. 215-229

Coulson, N. Edward, Joseph V. Terza, Cheryl A. Neslusan, Bruce C. Stuart, May, 1995, "Estimating the Moral-Hazard Effect of Supplemental Medical Insurance in the Demand for Prescription Drugs by the Elderly," American Economic Review, Vol. 85, No. 2., pp. 122-126

Cunningham, Peter J. and Linda Kohn, May/June 2000, "Health plan Switching: Choice or Circumstance?, Health Affairs, Volume 19, Number 3, pp.158-164

Duchon Lisa, Schoen Cathy, Simantov Elizabeth, Karen Davis, and Christina An, January 2000, "Listening to Workers: Findings from The Commonwealth fund 1999 National Survey of Workers' Health insurance", www.abtassoc.com 
Elo, Irma T. and Samuel H. Preston, 1996, “Educational Differentials in Mortality: United States, 1979-85," Social Science and Medicine 42(1), pp. $44-57$

Feldman J. D. Makuc, J. Kleinman and J. Cornoni-Huntley, 1989, "National Trends in Educational Differences in Mortality," American Journal of Epidemiology, pp. 919-933

Fuchs, Victor R. and Harold C. Sox Jr., "Physicians' View of the Relative Importance of Thirty Medical innovations," Health Affairs, Volume 20, Number 5, September/October 2001

Goldman, Dana and Darius Lakdawalla, June 2001, "Understanding Health disparities across education groups," NBER Working paper 8328

Goldman, Dana P. and James P. Smith, June 2001"Can Patient SelfManagement Explain the SES Health Gradient," RAND Working Paper

Grossman, Michael, 1972, "On the Concept of Health Capital the Demand for Health," Journal of Political Economy 80, (Illinois, United States) 223-255

Grossman, Michael and R. Kaestner, 1997, "Effects of Education on Health," in J.R. Berhman and N. Stacey Eds., The Social Benefits of Education, University of Michigan Press, pp. 223-255

Hurd, Michael, Daniel McFadden, Angela Merill and Tiago Ribeiro, forthcoming, "Healthy, Wealthy, and Wise? New Evidence from AHEAD Wave 3," Journal of Econometrics

Kaiser Foundation, November 2001, "Understanding the Effects of Directto-Consumer Prescription Drug Advertising," report, www. kff.org

Kenkel, Donald, April 1991, "Health Behavior, Health knowledge and Schooling," Journal of Political Economy, Volume 99, Issue 2, pp. 287305

Leigh, J. Paul and Rachna Dhir, 1997, "Schooling and Frailty Among Seniors," Economics of Education Review, Volume 16, No. 1, pp. 45-57

Lichtenberg, Frank R., May 1996, "Do (More and Better) Drugs Keep People Out of Hospitals?", American Economic Review 86, pp. 384-8. 
Lichtenberg, Frank R. September/October 2001 "Are the Benefits and Costs of Newer Drugs Worth Their Cost? Evidence from the 1996 MEPS," Health Affairs 20(5), pp. 241-51.

Lichtenberg, Frank R., forthcoming, "Pharmaceutical Knowledge-Capital Accumulation and Longevity," in Measuring Capital in the New Economy, ed. by Carol Corrado, John Haltiwanger, and Dan Sichel, (University of Chicago Press)

Lichtenberg, Frank R. and Thomas J. Philipson, April 2001, "The Dual Effects of intellectual Property Regulations: Within- and Between-Patent Competition in the US Pharmaceutical Industry," mimeo,

Lichtenberg, Frank R., and Suchin Virabhak, 2001, "Pharmaceuticalembodied technical progress, longevity, and quality of life: drugs as 'equipment for your health," Columbia University, mimeo

Lillard, Lee A., Jeannette Rogowski, and Raynard Kington. 1999, "Insurance Coverage for Prescription Drugs: Effects on Use and Expenditures in the Medicare Population." Medical Care, vol. 37, No. 9, pp. 926-936

Lleras-Muney, Adriana, May 2001, "The Relationship Between Education and Adult Mortality in the United States," NBER Working paper \#8986

Meara, Ellen, April 2001, "Why is health related to socio-economic Status? The case of pregnancy and low birth weight," NBER Working Paper

Meer, Jonathan, Douglas Miller and Harvey S. Rosen, August 2001, "Exploring the Health-Wealth Nexus," mimeo, Princeton University

Nelson, Richard R. and Edmund S. Phelps, 1966, "Investment in Humans, Technological Diffusion and Economics Growth," American Economic Review, pp. 69-75

Pappas, Gregory, Susan Queen, Wolber Hadden and Grail Fisher, 1993, "The Increasing Disparity in Mortality Between Socioeconomic Groups in the United States, 1960 and 1986," The New England Journal of Medicine, pp. 103-109

Rosenzweig, Mark R., May 1995, "Why are there returns to Schooling?," American Economic Review, Volume 85, Issue 2, pp. 153-158 
Rosenzweig, Mark R. and T. Paul Schultz, May 1989, 'Schooling, Information and Nonmarket Productivity: Contraceptive Use and its effectiveness," International Economic Review, 30920. pp. 457-77

Sander, William, 1995, "Schooling and Quitting Smoking," Review of Economics and Statistics, 77,pp. 191-199

Schwartz, RK, Avorn J. Soumerai and Jerry Avorn, 1989, "Physician Motivation for non-scientific drug prescribing," Social Science and Medicine, vol. 28, pp. 577-582

Sorensen, Alan T., October 2001, "An Empirical Model of Heterogeneous Consumer Search for Retail Prescription Drugs," NBER Working Paper No. W8548

Temin, Peter, May 1980, "Regulation and the Choice of Prescription Drugs," American Economic Review, Volume 70, Issue 2, Papers and Proceedings of the Ninety-Second Annuals Meeting of the American Economic Association, pp. 301-305 


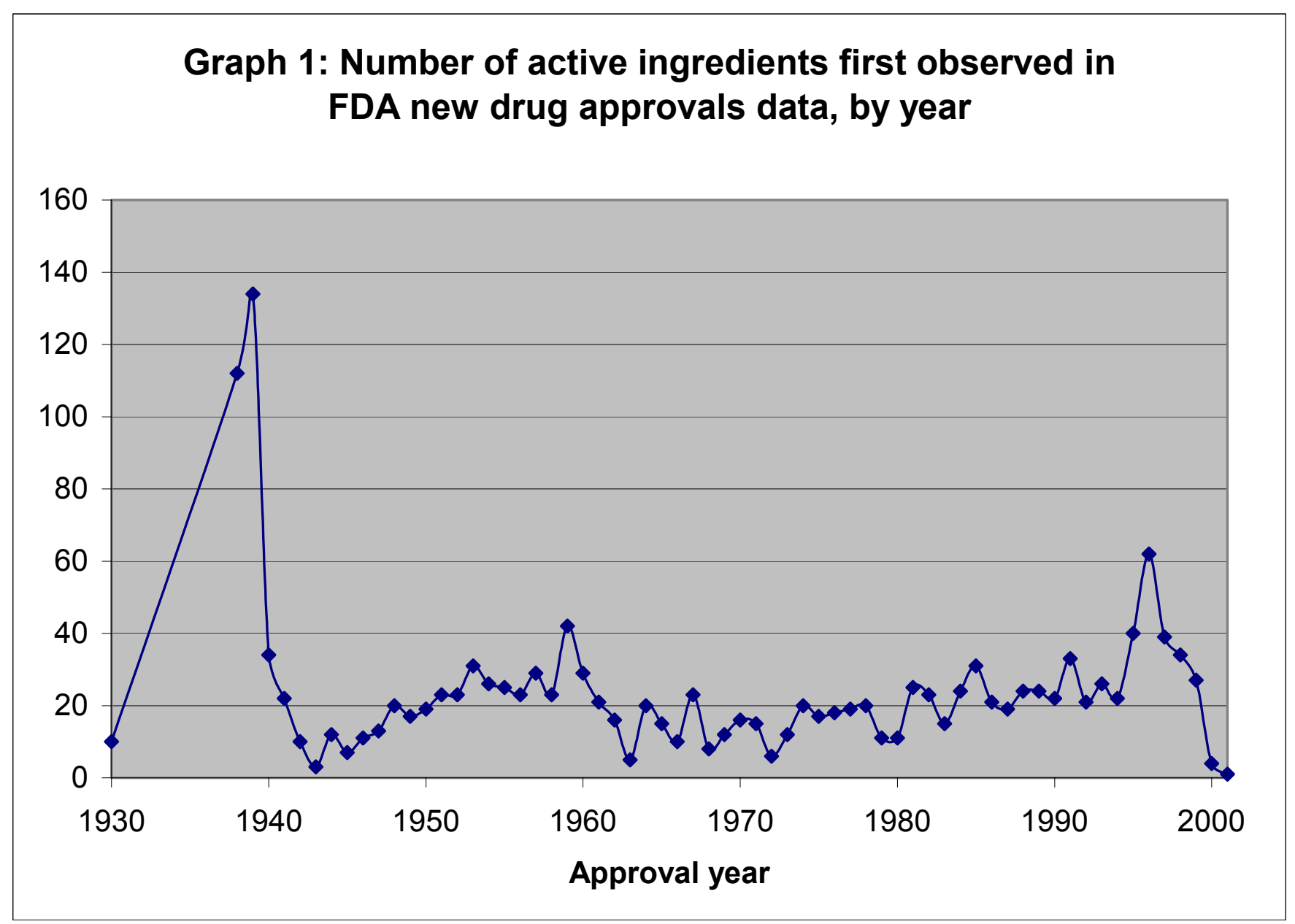


Table 1: Summary Statistics

Prescription Level Data

\begin{tabular}{|c|c|c|c|c|c|c|}
\hline \multirow[b]{2}{*}{ Variable } & \multicolumn{2}{|c|}{ All } & $E \mathrm{Ed}<12$ & \multicolumn{3}{|c|}{$E d>=12$} \\
\hline & Mean & Std. Dev. & Mean & Std. Dev. & Mean & Std. Dev. \\
\hline \# of years since drug was & & & & & & \\
\hline approved & 25.876 & 17.855 & 25.920 & 17.767 & 25.855 & 17.896 \\
\hline Age & 58.501 & 15.825 & 64.024 & 15.059 & 55.891 & 15.504 \\
\hline Completed years of education & 11.862 & 3.337 & 8.121 & 2.592 & 13.629 & 1.868 \\
\hline Married (=1) & 0.565 & 0.496 & 0.491 & 0.500 & 0.601 & 0.490 \\
\hline White $(=1)$ & 0.851 & 0.356 & 0.809 & 0.393 & 0.870 & 0.336 \\
\hline In urban area $(\mathrm{MSA}=1)$ & 0.709 & 0.454 & 0.599 & 0.490 & 0.762 & 0.426 \\
\hline Female $(=1)$ & 0.658 & 0.474 & 0.669 & 0.471 & 0.653 & 0.476 \\
\hline Income $0-10 \mathrm{~K}$ & 0.433 & 0.496 & 0.671 & 0.470 & 0.321 & 0.467 \\
\hline Income $10-20 \mathrm{~K}$ & 0.224 & 0.417 & 0.213 & 0.410 & 0.229 & 0.420 \\
\hline Income $20-30 \mathrm{~K}$ & 0.127 & 0.333 & 0.069 & 0.253 & 0.155 & 0.362 \\
\hline Income $30-40 \mathrm{~K}$ & 0.089 & 0.284 & 0.030 & 0.170 & 0.116 & 0.321 \\
\hline Income $40-50 \mathrm{~K}$ & 0.047 & 0.211 & 0.008 & 0.089 & 0.065 & 0.246 \\
\hline Income $50-60 \mathrm{~K}$ & 0.031 & 0.174 & 0.002 & 0.044 & 0.045 & 0.207 \\
\hline Income $60-70 \mathrm{~K}$ & 0.016 & 0.124 & 0.003 & 0.051 & 0.022 & 0.146 \\
\hline Income $70-80 \mathrm{~K}$ & 0.014 & 0.117 & 0.001 & 0.037 & 0.020 & 0.139 \\
\hline Income $80-90 \mathrm{~K}$ & 0.005 & 0.074 & 0.002 & 0.040 & 0.007 & 0.085 \\
\hline Income $90-100 \mathrm{~K}$ & 0.002 & 0.045 & 0.001 & 0.035 & 0.002 & 0.049 \\
\hline Income $100-110 \mathrm{~K}$ & 0.004 & 0.062 & 0.000 & 0.000 & 0.006 & 0.075 \\
\hline Income $110-120 \mathrm{~K}$ & 0.004 & 0.065 & 0.000 & 0.000 & 0.006 & 0.079 \\
\hline Income $120-130 \mathrm{~K}$ & 0.001 & 0.026 & 0.000 & 0.010 & 0.001 & 0.031 \\
\hline Income $130-140 \mathrm{~K}$ & 0.001 & 0.028 & 0.000 & 0.000 & 0.001 & 0.033 \\
\hline Income $140-150 \mathrm{~K}$ & 0.001 & 0.031 & 0.000 & 0.000 & 0.001 & 0.038 \\
\hline Income $150 \mathrm{~K}+$ & 0.001 & 0.038 & 0.000 & 0.000 & 0.002 & 0.047 \\
\hline Has Private Insurance c & 0.650 & 0.477 & 0.423 & 0.494 & 0.757 & 0.429 \\
\hline Has Public Insurance only $(=1)$ & 0.298 & 0.457 & 0.516 & 0.500 & 0.194 & 0.396 \\
\hline Approved after 1970 & 0.559 & 0.496 & 0.565 & 0.496 & 0.556 & 0.497 \\
\hline Approved after 1980 & 0.438 & 0.496 & 0.447 & 0.497 & 0.434 & 0.496 \\
\hline Approved after 1990 & 0.182 & 0.386 & 0.171 & 0.377 & 0.187 & 0.390 \\
\hline Age of the drug imputed $(=1)$ & 0.122 & 0.327 & 0.106 & 0.308 & 0.130 & 0.336 \\
\hline $\begin{array}{l}\text { Number of physician visits in } \\
\text { year }\end{array}$ & 9.384 & 11.350 & 9.009 & 9.211 & 9.561 & 12.227 \\
\hline $\begin{array}{l}\% \text { payment paid by self for } \\
\text { prescription } \\
\% \text { prescriptions paid by }\end{array}$ & 0.585 & 0.424 & 0.607 & 0.444 & 0.574 & 0.414 \\
\hline self/family in year & 0.522 & 0.350 & 0.554 & 0.373 & 0.507 & 0.338 \\
\hline $\begin{array}{l}\text { Total health care expenditures in } \\
\text { year }\end{array}$ & 7485.49 & 12337.86 & 8501.65 & 13969.12 & 7005.3 & 11455.53 \\
\hline Self reported bad health & 0.155 & 0.362 & 0.250 & 0.433 & 0.111 & 0.314 \\
\hline Number of hospital visits in year & 0.372 & 1.059 & 0.424 & 0.988 & 0.347 & 1.091 \\
\hline $\begin{array}{l}\text { Number of prescriptions by } \\
\text { condition }\end{array}$ & 4.342 & 3.688 & 4.390 & 3.740 & 4.319 & 3.787 \\
\hline
\end{tabular}

Sample: Individuals aged 25 and above. Data 1997 MEPS. N=163,081. 
Table 2: Effect of education of the age of drug consumed

\begin{tabular}{|c|c|c|c|c|c|c|}
\hline \multicolumn{7}{|c|}{$\begin{array}{r}\text { Basic regressions } \\
\end{array}$} \\
\hline \multirow[t]{2}{*}{ Education } & $-0.158 * *$ & $0.004 * *$ & $0.003 *$ & $0.004 * *$ & $-0.116 * *$ & $-0.158 * *$ \\
\hline & $(0.045)$ & $(0.001)$ & $(0.001)$ & $(0.001)$ & $(2.0 \mathrm{e}-04)$ & $(0.045)$ \\
\hline Married & $(0.250)$ & $(0.007)$ & $(0.007)$ & $(0.006)$ & $(0.001)$ & $(0.250)$ \\
\hline \multirow[t]{2}{*}{ White } & $-1.501 * *$ & $0.032 * *$ & $0.036 * *$ & 0.015 & $-0.245 * *$ & $-1.473 * *$ \\
\hline & $(0.349)$ & $(0.010)$ & $(0.010)$ & $(0.008)$ & $(0.002)$ & $(0.348)$ \\
\hline \multirow{2}{*}{ Urban } & 0.084 & -0.004 & -0.000 & 0.004 & $0.094 * *$ & 0.088 \\
\hline & $(0.277)$ & $(0.008)$ & $(0.008)$ & $(0.007)$ & $(0.002)$ & $(0.277)$ \\
\hline Female & 0.306 & -0.012 & -0.014 & 0.003 & $3.440 * *$ & 0.288 \\
\hline \multirow[t]{2}{*}{ Public Insurance $(=1)$} & -0.615 & 0.015 & 0.033 & $0.040 * *$ & $-1.137 * *$ & -0.597 \\
\hline & $(0.553)$ & $(0.019)$ & $(0.017)$ & $(0.014)$ & $(0.003)$ & $(0.553)$ \\
\hline \multirow[t]{2}{*}{ Age of the drug imputed $(=1)$} & & & & & & $1.344^{* *}$ \\
\hline & & & & & & $(0.380)$ \\
\hline 16 income category dummies & yes & yes & yes & yes & yes & yes \\
\hline R-squared & 0.27 & 0.27 & 0.26 & 0.14 & & 0.27 \\
\hline
\end{tabular}

Notes: Data: 1997 MEPS. N = 163081. Sample: All prescriptions for individuals aged 25 and above with no missing values. Regressions include region of residence dummies, single years of age dummies and 3 digit level condition dummies. Standard errors (in parenthesis) are clustered at the person level.

(a) dependent variable right censored at 54. A random effects tobit model would not converge, therefore the errors are not clustered here.

* significant at $5 \%$; * significant at $1 \%$ 


\section{Table 3: Effect of education of the age of drug consumed Further control for insurance}

Dependent Variable:

Age of drug

$\begin{array}{ccccc}\text { Basic } & \% \text { price } & \% & \text { Break } & \text { Doctor } \\ \text { regressi } & \text { paid by } & \text { prescrip } & \text { down } \\ \text { on } & \text { self }^{(a)} & \text { tions } & \text { insuran } & \\ & & \text { self } & \text { ce } & \\ & & \text { pays } & \text { coverag } \\ & & & \text { e } & \end{array}$

Education

$-0.158 * *-0.169 * *$

$\begin{array}{lllll}(0.045) & (0.046) & (0.045) & (0.045) & (0.045)\end{array}$

Married

$-0.568 * \quad-0.499 *$

$-0.539 *$

$-0.534 *$

$-0.572 *$

$\begin{array}{lllll}(0.250) & (0.249) & (0.248) & (0.254) & (0.250)\end{array}$

$\begin{array}{lllll}-1.501 * * & -1.632 * * & -1.553 * * & -1.530 * * & -1.492 * *\end{array}$

White

(0.349)

$(0.350)$

(0.350)

(0.346)

0.165

(0.349)

0.084

0.417

0.264

(0.277)

0.086

$(0.277)$

(0.276)

$(0.276)$

0.351

(0.277)

0.306

0.228

0.268

(0.270)

0.312

$(0.269)$

$-1.604 * *$

(0.270)

(0.269)

$-0.443$

(0.513)

$(0.524)$

(0.539)

$(0.269)$

$-0.615$

$1.969^{* *}$

0.633

(0.553)

(0.567)

$5.990^{* *}$

(0.579)

(0.278)

2.573**

(0.366)

$\%$ paid by other sources is left out category

$\%$ of medical expenditures paid by Medicaid

$\%$ of medical expenditures paid by Medicare

$\%$ of medical expenditures paid by private insurance

$\%$ of medical expenditures paid by self

\# office-based physician visits

$-0.309$

$(0.953)$

0.310

(0.997)

$-1.978^{*}$

$(0.815)$

$-0.076$

$(0.885)$

$-0.005$

$(0.011)$

16 income category dummies

Condition dummies

yes yes yes yes yes

\begin{tabular}{ccccc} 
yes & yes & yes & yes & yes \\
yes & yes & yes & yes & yes \\
0.27 & 0.29 & 0.27 & 0.27 & 0.27 \\
\hline
\end{tabular}

$\begin{array}{lllll}0.27 & 0.29 & 0.27 & 0.27 & 0.27\end{array}$

Notes: Data: 1997 MEPS. $N=163081$. Sample: All prescriptions for individuals aged 25 and above with no missing values. Regressions include region of residence dummies, single years of age dummies and 3 digit level condition dummies. Standard errors (in parenthesis) are clustered at the person level.

(a) $\mathrm{N}=163079$ when including $\%$ price paid by self for prescription

* significant at $5 \% ; * *$ significant at $1 \%$ 
Table 4: Effect of education of the age of drug consumed Person level results. Control for Severity

\begin{tabular}{|c|c|c|c|c|}
\hline $\begin{array}{l}\text { Dependent variable: } \\
\text { Age of drug in years }\end{array}$ & $\begin{array}{c}\text { Basic } \\
\text { regression }\end{array}$ & $\begin{array}{l}\text { Hospital } \\
\text { visits }\end{array}$ & $\begin{array}{c}\text { Bad } \\
\text { Health }^{(a)}\end{array}$ & $\begin{array}{c}\text { Total } \\
\text { expenditures }\end{array}$ \\
\hline Education & $\begin{array}{c}-0.158 * * \\
(0.045)\end{array}$ & $\begin{array}{c}-0.158 * * \\
(0.045)\end{array}$ & $\begin{array}{c}-0.158 * * \\
(0.045)\end{array}$ & $\begin{array}{c}-0.157^{* *} \\
(0.044)\end{array}$ \\
\hline Married & $\begin{array}{c}-0.568 * \\
(0.250)\end{array}$ & $\begin{array}{c}-0.564^{*} \\
(0.250)\end{array}$ & $\begin{array}{c}-0.585^{*} \\
(0.251)\end{array}$ & $\begin{array}{l}-0.565^{*} \\
(0.251)\end{array}$ \\
\hline White & $\begin{array}{c}-1.501 * * \\
(0.349)\end{array}$ & $\begin{array}{c}-1.502 * * \\
(0.349)\end{array}$ & $\begin{array}{c}-1.503 * * \\
(0.352)\end{array}$ & $\begin{array}{l}-1.509 * * \\
(0.349)\end{array}$ \\
\hline Urban & $\begin{array}{c}0.084 \\
(0.277)\end{array}$ & $\begin{array}{c}0.089 \\
(0.277)\end{array}$ & $\begin{array}{c}0.039 \\
(0.279)\end{array}$ & $\begin{array}{c}0.091 \\
(0.277)\end{array}$ \\
\hline Female & $\begin{array}{c}0.306 \\
(0.269)\end{array}$ & $\begin{array}{c}0.305 \\
(0.269)\end{array}$ & $\begin{array}{c}0.318 \\
(0.270)\end{array}$ & $\begin{array}{c}0.309 \\
(0.268)\end{array}$ \\
\hline Private insurance $(=1)$ & $\begin{array}{c}-1.604 * * \\
(0.513)\end{array}$ & $\begin{array}{c}-1.609 * * \\
(0.514)\end{array}$ & $\begin{array}{c}-1.606^{* *} \\
(0.512)\end{array}$ & $\begin{array}{c}-1.623 * * \\
(0.514)\end{array}$ \\
\hline Public insurance $(=1)$ & $\begin{array}{l}-0.615 \\
(0.553)\end{array}$ & $\begin{array}{l}-0.631 \\
(0.553)\end{array}$ & $\begin{array}{l}-0.632 \\
(0.553)\end{array}$ & $\begin{array}{l}-0.631 \\
(0.555)\end{array}$ \\
\hline Number of hospital visits in year & & $\begin{array}{c}0.049 \\
(0.170)\end{array}$ & & \\
\hline Self reported bad health & & & $\begin{array}{c}0.176 \\
(0.398)\end{array}$ & \\
\hline $\begin{array}{l}\text { Total health care expenditures in } \\
\text { year }\end{array}$ & & & & $\begin{array}{c}0.000 \\
(0.000)\end{array}$ \\
\hline $\begin{array}{l}16 \text { income dummies } \\
\mathrm{R} \text {-squared }\end{array}$ & $\begin{array}{l}\text { yes } \\
0.27\end{array}$ & $\begin{array}{l}\text { yes } \\
0.27\end{array}$ & $\begin{array}{l}\text { yes } \\
0.27\end{array}$ & $\begin{array}{l}\text { yes } \\
0.27\end{array}$ \\
\hline
\end{tabular}

Notes: Data: 1997 MEPS. N = 163081. Sample: All prescriptions for individuals aged 25 and above with no missing values. Regressions include region of residence dummies, single years of age dummies and 3 digit level condition dummies. Standard errors (in parenthesis) are clustered at the person level.

(a) $\mathrm{N}=161,359$ when including self reported bad health

* significant at $5 \%$; * significant at $1 \%$ 
Table 5: Effect of education of the age of drug consumed By disease categories

\begin{tabular}{|c|c|c|c|c|}
\hline & $\mathrm{Beta}^{(\mathrm{a})}$ & s.e. & $\overline{\mathrm{N}}$ & R-squared \\
\hline \multicolumn{5}{|l|}{ By broad disease categories ${ }^{(b)}$} \\
\hline Infectious and parasitic diseases & 0.097 & $(0.187)$ & 2831 & 0.25 \\
\hline Cancer (Neoplasms) & 0.623 & $(0.383)$ & 1457 & 0.36 \\
\hline Endocrine, nutritional, metabolic and immunity disorders & 0.014 & $(0.1)$ & 22546 & 0.59 \\
\hline Disease of blood and blood forming organs & $1.319 *$ & $(0.671)$ & 563 & 0.75 \\
\hline Mental disorders & -0.115 & $(0.136)$ & 10835 & 0.23 \\
\hline Diseases or the nervous systems and sense organs & $-0.688 * *$ & $(0.188)$ & 8430 & 0.23 \\
\hline Cardiovascular diseases & $-0.183 *$ & $(0.086)$ & 41645 & 0.13 \\
\hline Respiratory system diseases & $-0.283 *$ & $(0.122)$ & 17433 & 0.08 \\
\hline Digestive system & 0.06 & $(0.138)$ & 7532 & 0.37 \\
\hline Diseases of the genitourinary system & 0.02 & $(0.14)$ & 6920 & 0.47 \\
\hline All Other & $-0.180 *$ & $(0.09)$ & 42889 & 0.2 \\
\hline \multicolumn{5}{|l|}{ For some common 3 digit ICD 9 diseases } \\
\hline Hypertension $($ ICD9 $\operatorname{code}=401)$ & -0.161 & $(0.093)$ & 25257 & 0.05 \\
\hline Chronic sinusitis (ICD9 $\operatorname{code}=473$ ) & -0.353 & $(0.222)$ & 2147 & 0.12 \\
\hline Diabetes $($ ICD9 $\operatorname{code}=250)$ & 0.265 & $(0.158)$ & 8129 & 0.13 \\
\hline Depression $($ ICD9 $\operatorname{code}=311)$ & 0.005 & $(0.188)$ & 5512 & 0.16 \\
\hline
\end{tabular}

Notes: Data: 1997 MEPS. Sample: All prescriptions for individuals aged 25 and above with no missing values.

(a) Each coefficient represents the effect of more more year of schooling and is obtained from separate regressions. Each regressions include all the controls used in previous tables. Standard errors (in parenthesis) are clustered at the person level.

(b) These broad categories were created by grouping icd9 codes at the two digit level as follows: as follows infection (13 and less), cancer (14-23) endocrine (24-27), blood (28-29), mental (29-31), nervous (32-38), cardiovascular (39-45), respiratory (46-51), digestive (52-57), urinary (58-62) and other (63 and above). In these regressions 3 -digit condition dummies (within category) were included.

* significant at $5 \%$; * significant at $1 \%$ 
Table 6: Effect of education by extent of prescription drug use

\begin{tabular}{|c|c|c|c|c|c|}
\hline $\begin{array}{l}\text { Dependent variable: Age of drug in } \\
\text { years }\end{array}$ & $\begin{array}{c}\text { All- } \\
\text { Basic } \\
\text { regression }\end{array}$ & $\begin{array}{c}1 \\
\text { prescription } \\
\text { for } \\
\text { condition }\end{array}$ & $\begin{array}{c}\text { Between } 2 \\
\text { and } 6 \\
\text { prescriptions } \\
\text { for the } \\
\text { condition } \\
\end{array}$ & $\begin{array}{l}7 \text { or more } \\
\text { prescriptions } \\
\text { by condition }\end{array}$ & $\begin{array}{c}\text { All- } \\
\text { Interaction } \\
\text { with log (\# } \\
\text { prescriptions } \\
\text { by condition) }\end{array}$ \\
\hline Education & $\begin{array}{c}-0.158 * * \\
(0.045)\end{array}$ & $\begin{array}{c}0.042 \\
(0.074)\end{array}$ & $\begin{array}{c}-0.194 * * * \\
(0.054)\end{array}$ & $\begin{array}{c}-0.269 * * \\
(0.113)\end{array}$ & $\begin{array}{c}0.021 \\
(0.065)\end{array}$ \\
\hline $\begin{array}{l}\text { Education } * \log (\text { number of } \\
\text { prescriptions for conditions })\end{array}$ & & & & & $\begin{array}{c}-0.160 * * * \\
(0.053) \\
2.690 * * *\end{array}$ \\
\hline $\begin{array}{l}\log (\text { number of prescriptions for } \\
\text { conditions) }\end{array}$ & & & & & $(0.684)$ \\
\hline $\mathrm{N}$ & 163,081 & 24,626 & 108,767 & 29,688 & 163,081 \\
\hline R-squared & 0.27 & 027 & 0.33 & 0.19 & \\
\hline
\end{tabular}

Notes: Data: 1997 MEPS. Sample: All prescriptions for individuals aged 25 and above with no missing values.

Each coefficient represents the effect of more more year of schooling and is obtained from separate regressions. Each regressions include all the controls used in previous tables. Standard errors (in parenthesis) are clustered at the person level. 
Table 7 Effect of education of the age of drug consumed By groups

\begin{tabular}{|c|c|c|c|c|c|}
\hline $\begin{array}{l}\text { Dependent variable: Age of drug in } \\
\text { years }\end{array}$ & A11 & Males & Females & Whites & Non-Whites \\
\hline Education & $\begin{array}{c}-0.158 * * \\
(0.045)\end{array}$ & $\begin{array}{c}-0.266^{* *} \\
(0.069)\end{array}$ & $\begin{array}{l}-0.091 \\
(0.053)\end{array}$ & $\begin{array}{c}-0.170 * * \\
(0.048)\end{array}$ & $\begin{array}{l}-0.018 \\
(0.115)\end{array}$ \\
\hline Married & $\begin{array}{l}-0.568 * \\
(0.250)\end{array}$ & $\begin{array}{l}-0.913 * \\
(0.431)\end{array}$ & $\begin{array}{l}-0.532 \\
(0.291)\end{array}$ & $\begin{array}{l}-0.610^{*} \\
(0.266)\end{array}$ & $\begin{array}{l}-0.931 \\
(0.651)\end{array}$ \\
\hline White & $\begin{array}{c}-1.501 * * \\
(0.349)\end{array}$ & $\begin{array}{l}-2.270 * * \\
(0.609)\end{array}$ & $\begin{array}{c}-1.172 * * \\
(0.388)\end{array}$ & & \\
\hline Urban & $\begin{array}{c}0.084 \\
(0.277)\end{array}$ & $\begin{array}{c}0.096 \\
(0.431)\end{array}$ & $\begin{array}{c}0.051 \\
(0.326)\end{array}$ & $\begin{array}{c}0.175 \\
(0.292)\end{array}$ & $\begin{array}{l}-1.087 \\
(0.706)\end{array}$ \\
\hline Private insurance $(=1)$ & $\begin{array}{c}0.306 \\
(0.269)\end{array}$ & $\begin{array}{l}-1.947^{*} \\
(0.879)\end{array}$ & $\begin{array}{l}-1.265 \\
(0.652)\end{array}$ & $\begin{array}{c}-1.686^{* *} \\
(0.572)\end{array}$ & $\begin{array}{l}-1.635 \\
(1.119)\end{array}$ \\
\hline Public insurance $(=1)$ & $\begin{array}{c}-1.604 * * \\
(0.513)\end{array}$ & $\begin{array}{l}-0.175 \\
(0.960)\end{array}$ & $\begin{array}{l}-0.712 \\
(0.697)\end{array}$ & $\begin{array}{l}-0.880 \\
(0.627)\end{array}$ & $\begin{array}{l}-0.463 \\
(1.164)\end{array}$ \\
\hline Female & $\begin{array}{l}-0.615 \\
(0.553)\end{array}$ & & & $\begin{array}{c}0.391 \\
(0.284)\end{array}$ & $\begin{array}{l}-1.335^{*} \\
(0.661)\end{array}$ \\
\hline 16 income dummies & yes & yes & yes & yes & yes \\
\hline $\begin{array}{l}\mathrm{N} \\
\mathrm{R} \text {-squared }\end{array}$ & $\begin{array}{c}163,081 \\
0.27\end{array}$ & $\begin{array}{c}55,708 \\
0.24\end{array}$ & $\begin{array}{c}107,373 \\
0.30\end{array}$ & $\begin{array}{c}138,716 \\
0.28\end{array}$ & $\begin{array}{c}24,365 \\
0.26\end{array}$ \\
\hline
\end{tabular}

Notes: Data: 1997 MEPS. N = 163081. Sample: All prescriptions for individuals aged 25 and above with no missing values. Regressions include region of residence dummies, single years of age dummies and 3 digit level condition dummies. Standard errors (in parenthesis) are clustered at the person level. * significant at $5 \%$; * $*$ significant at $1 \%$ 


\section{Graph 2}

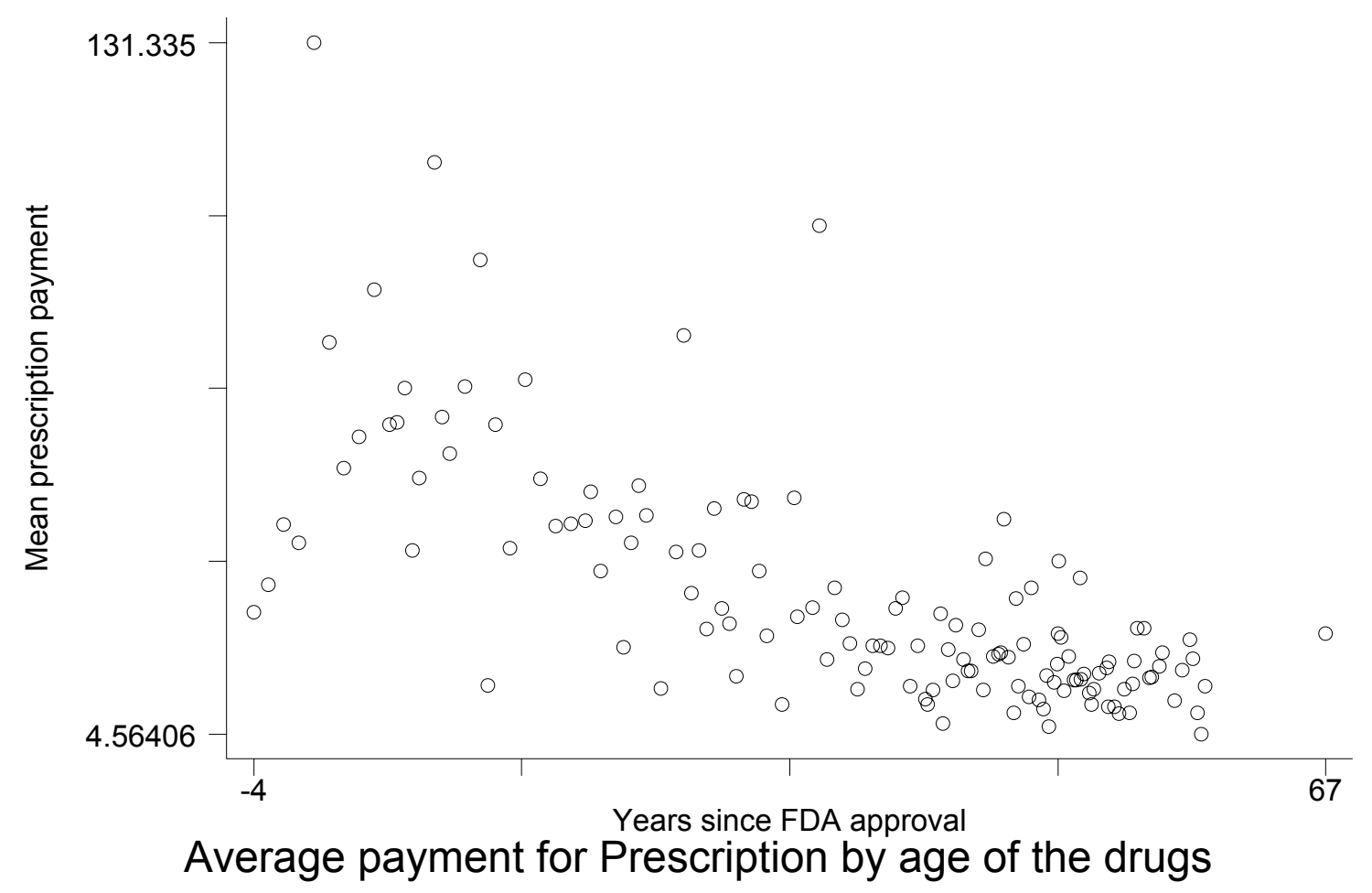

\section{Graph 3}

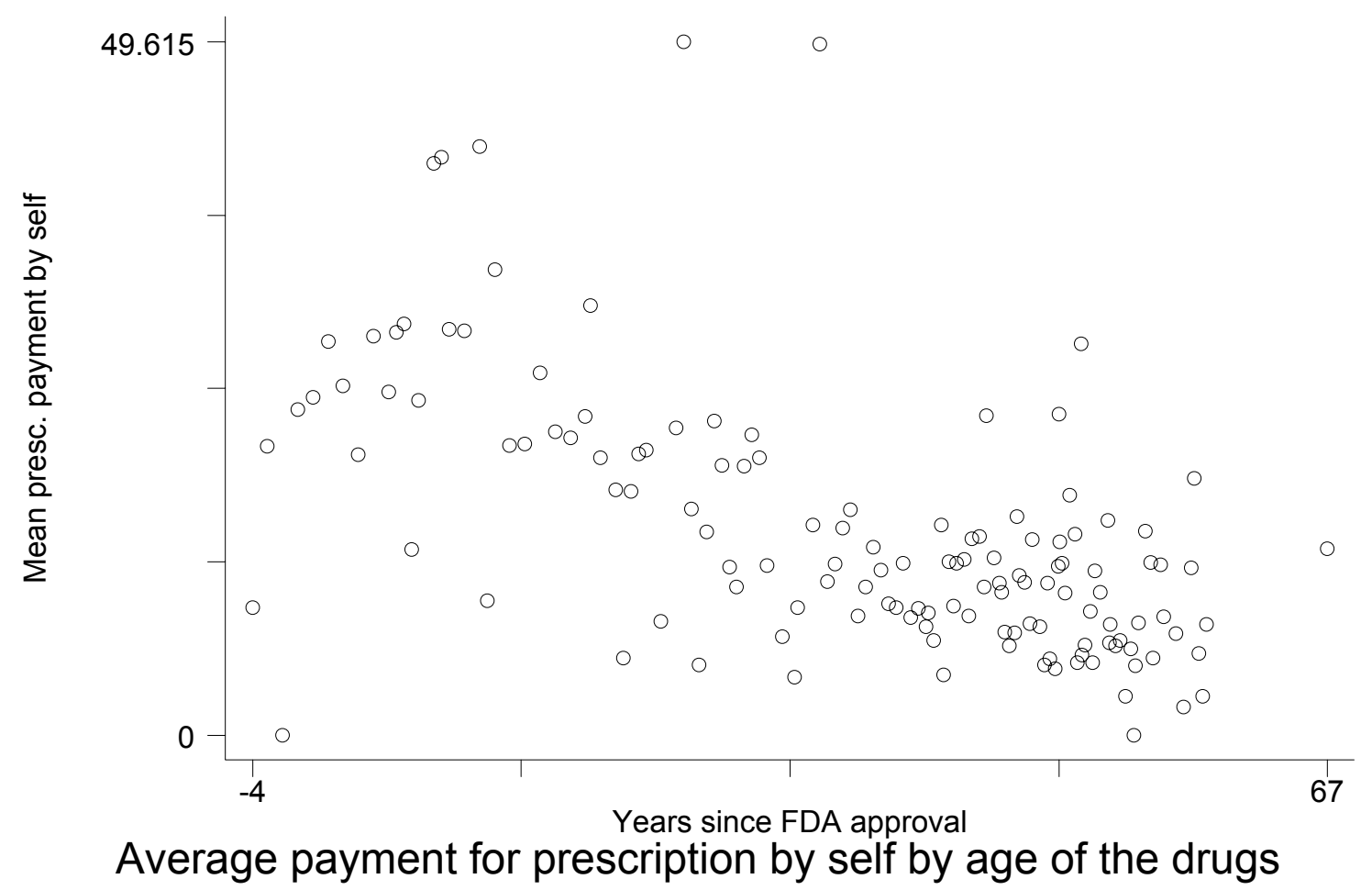




\section{Graph 4}

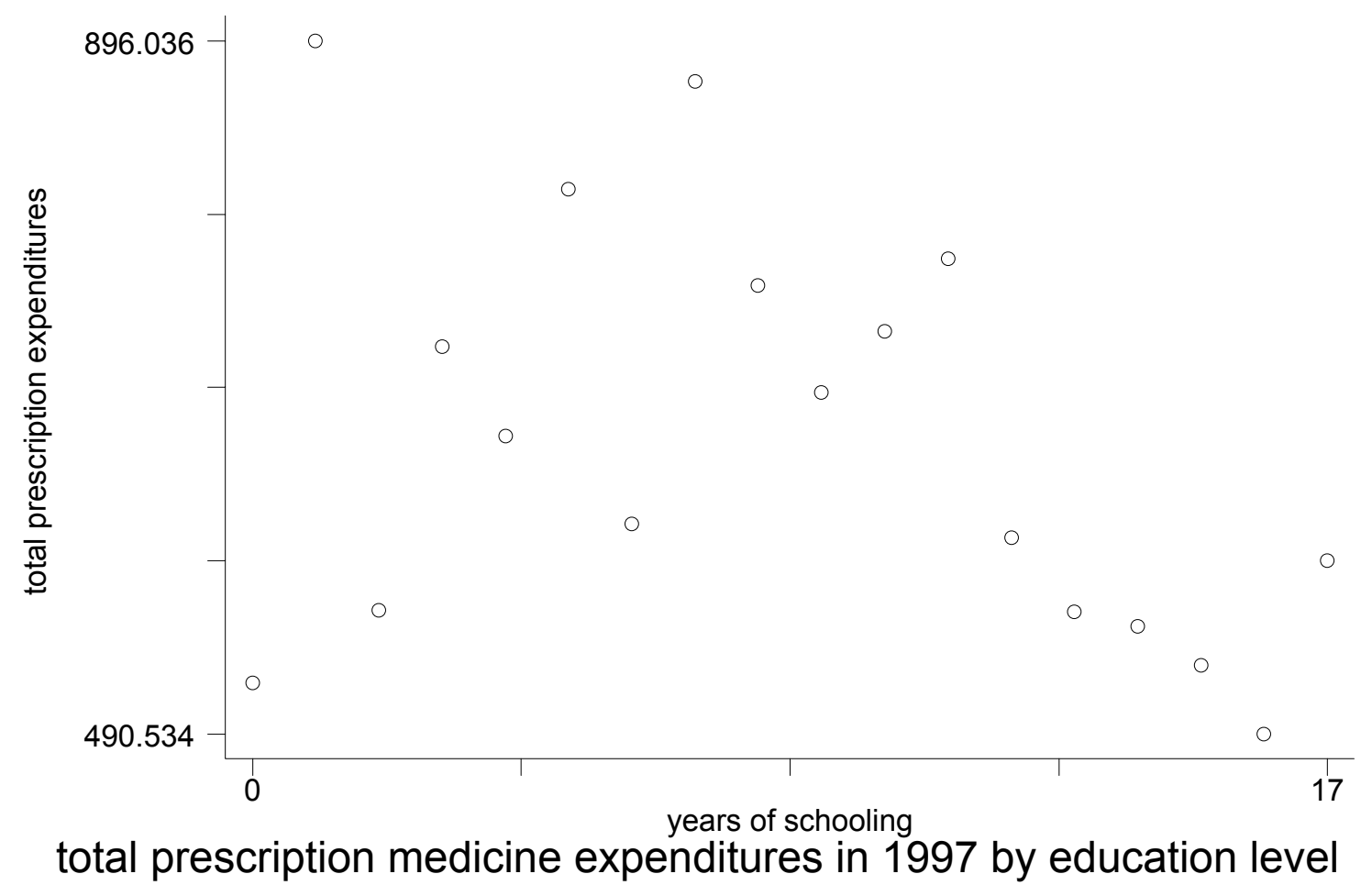

\section{Graph 5}

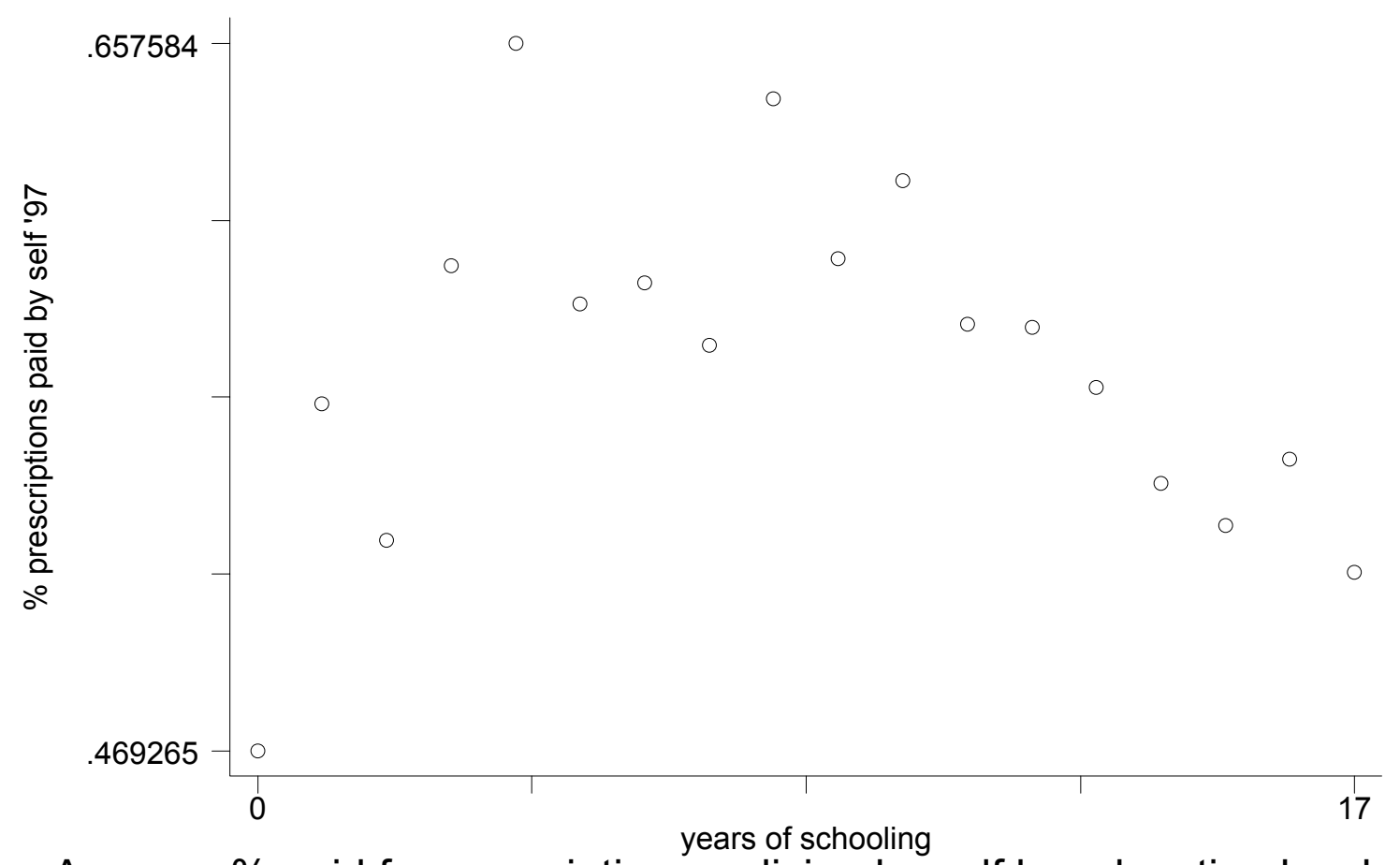

Average $\%$ paid for prescription medicine by self by education level 


\section{Graph 6}

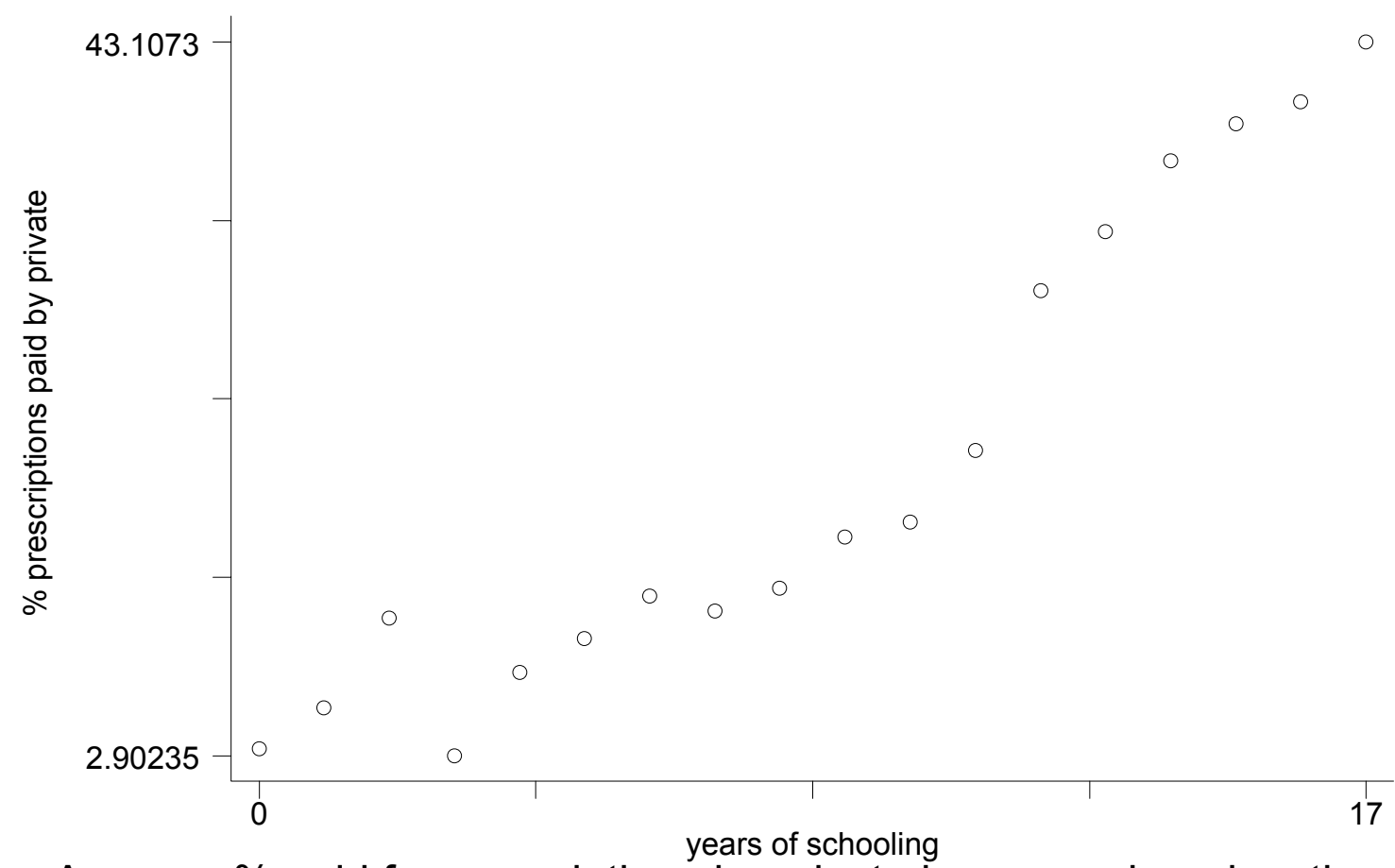

Average \% paid for prescriptions by private insurance by education

\section{Graph 7}

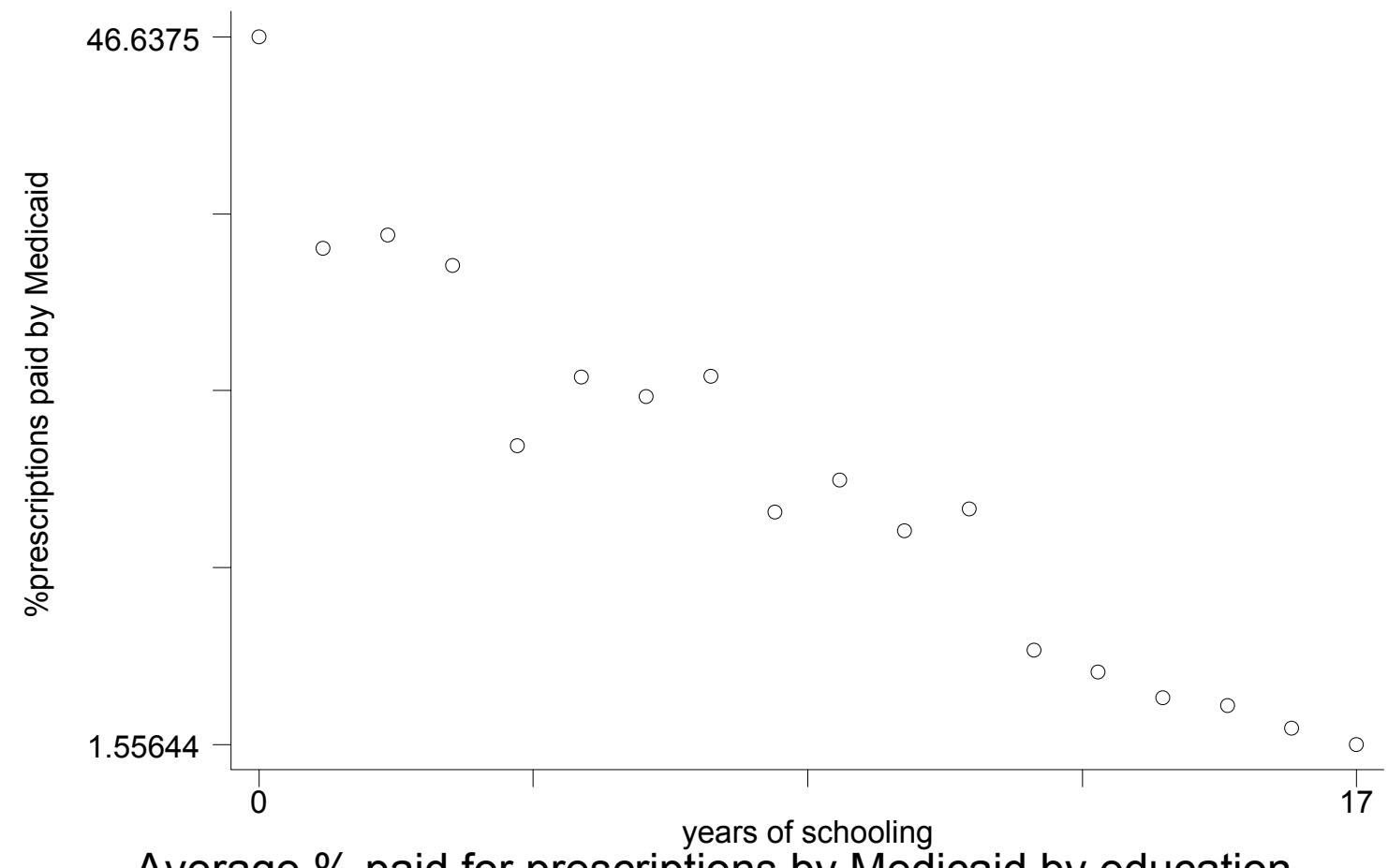

Average \% paid for prescriptions by Medicaid by education 